\title{
Design of 45,000-Kv-a. Generators, Queenston Plant
}

\author{
BY R. A. McCARTY \\ Associate, A. I. E. E. \\ and \\ Westinghouse Electric and Manufacturing Company
}

\author{
H. U. HART \\ Fellow, A. I. E. E. \\ Canadian Westinghouse Company
}

\begin{abstract}
The water power development at Queenston, Ontario, which made use of the combined head of Niagara Falls and the Niagara River Rapids below the Falls, involved the design and construction of, what up to the present time are the largest hydroelectric generators built. Owing to the size limits met in these generators certain interesting design problems were encountered. The more important of these problems dealt with the design of (1) the armature winding, (2) the upper bearing bracket and (3) the rotating spider. The solution of these problems is briefly discussed and a tabulation of major dimensions and weights of the generators is given.
\end{abstract}

$\mathrm{T}$ HE initial installation at the Queenston Development of the Hydro-Electric Power Commission of Ontario consists of two vertical shaft type alternating-current generators, each rated at 45,000 kv-a., 12,000 volts, 80 per cent power factor, three-phase, 25 cycles, $1871 \frac{1}{2}$ rev. per min. nominal, or $49,500 \mathrm{kv}-\mathrm{a}$., 13,200 volts maximum. A third duplicate unit will shortly follow the first two machines.

These units, as far as the records show, are the largest hydroelectric generators yet built and put into service. On account of their size, both in kilovolt-ampere rating and in physical proportions some interesting design problems were raised. These problems were divided into two classes, (1) electrical, and (2) mechanical, with perhaps the latter predominating.

Fig. 1 gives a sectional view of the generator unit. Fig. 2 gives a sectional view of the generator turbine and surrounding structure and indicates the flow of the cooling air through the generator and ducts. Each unit consists of the following component parts:

Stationary armature with base ring.

Upper bearing bracket, which supports the upper guide bearing and the thrust bearing.

Kingsbury thrust bearing.

Revolving field.

Shaft, with one-half coupling forged on the lower end for connection to the turbine shaft.

Lower bearing bracket, which carries the lower guide bearing, brakes and lifting jacks.

Direct-connected exciter.

\section{Design of ARMature Winding}

The design of the armature winding involved, in addition to the ordinary questions of heating, efficiency, etc., the solutions of four important special problems, namely, (a) to obtain a distribution of the armature coils such as to produce a resultant voltage wave practically free from interference with adjacent telephone lines, (b) to obtain sufficient cross-section of copper in the armature coils to carry successfully the rated current, and at the same time not have the conductors of such proportions as to result in excessive eddy current loss; (c) to insulate the coils with materials that could meet the requirements for high dielectric tests and a

Presented at the Annual Convention of the A. I. E. E., Niagara Falls, Ontario, June 26-30, 1922. high maximum temperature limit, even though the operating temperatures are low; and (d) so to support the end windings as to enable them to resist the enormous stresses that would be set up under short-circuit conditions.

The solutions worked out for these design problems were as follows:

(a) It is a well understood condition in the design of electrical generators that starting with the usual

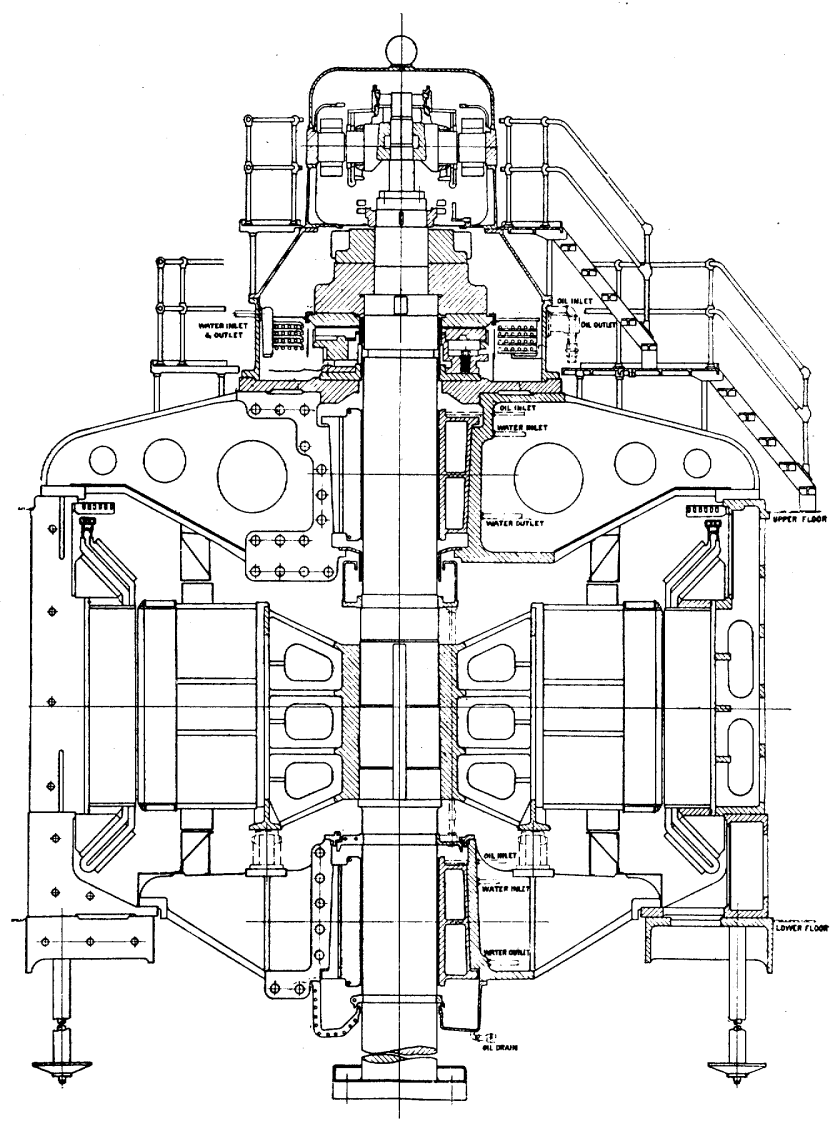

Fig. 1-Cross Section of Generator

field flux form, the actual resultant wave will more nearly follow the desired law, other factors being the same, provided that the conductors, producing the resultant wave, are distributed at a maximum number of different positions about the armature periphery; $i . e$, in a maximum number of slots. It was not found possible in these units to use an actual number of slots sufficiently large to insure the desired results. However the same effect was obtained by employing 
instead of the usual whole number of slots per pole a fractional number of slots per pole. The design selected had $191 / 2$ slots per pole which gave a distribution of the winding equivalent to 39 slots per pole. Fig. 3 indicates the distribution of the slots in two successive poles. One pole is shown directly above the other to indicate the relative phase position of the slots.

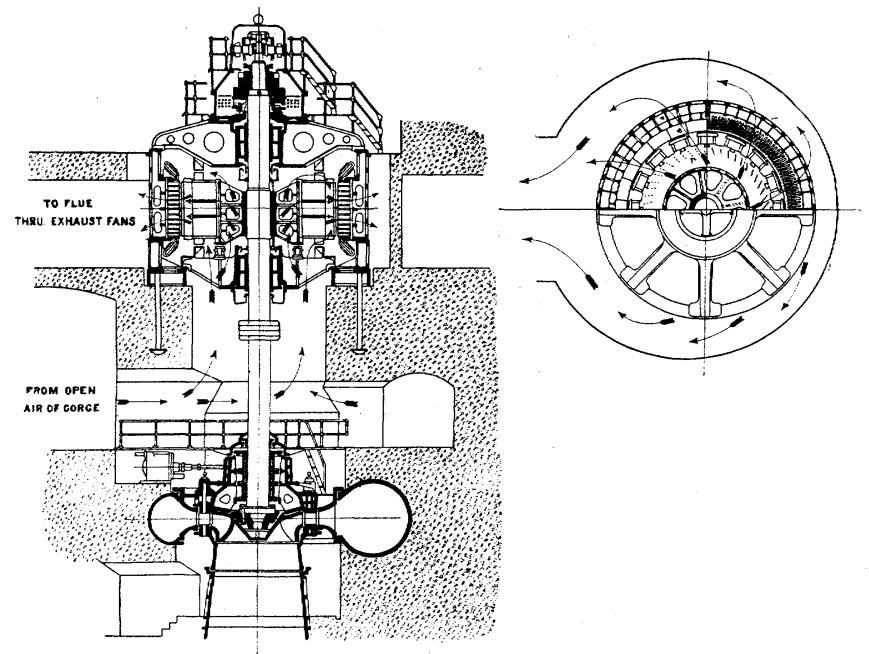

Fig. 2-Showing Fiow of Cooling Air

Since the slots per phase in successive poles, in series, are displaced one-half slot pitch with reference to each other, it is apparent that the effect is equivalent to double the actual number of slots per pole.

(b) To minimize the eddy current loss it is necessary (1) to keep the over-all dimensions of the conductors (groups of wires in parallel) small, and (2) to reduce the dimensions, at right angles to the direction of the fluxes, of the individual wires that form the conductors, to relatively small values. To accomplish these results the total copper cross-section per phase was divided into four parallel circuits and the conductor in each of these circuits was subdivided as shown in the slot cross-section, Fig. 4. Each slot contains two coil sides consisting of two conductors each, $i$. e., four conductors per slot, made up of nine wires in parallel per conductor. Each conductor is divided, depthwise of

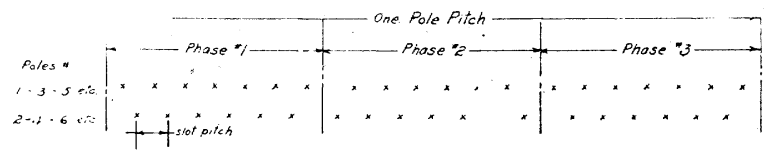

Fig. 3-Armature Winding Distribution $\times$ Represents a slot

the slot, into seven layers, in consideration of the effect of the flux of self-induction. The two layers nearest the air gap were again subdivided into two parts in the width of the slot. The coil was also sunk in the core an additional distance over that ordinarily required for the slot wedge. The latter two features were to minimize the effect of the air gap flux that fringes into the slot.

Each of the wires marked " $A$ " in Fig. 4 was insulated throughout its entire length with mica tape to insure positive and permanent separation between the various strands.

Since all the wires are continuous throughout the length of the coil the subdivision, of course, repeats itself in each conductor.

(c) Each group of wires forming a single conductor was insulated with mica tape. The conductors were assembled with mica strips between them to form the coil. The straight section of the coil which is embedded in the armature slot was brushed with bakelite, and then pressed in a hot press to solidify and consolidate the wires. The result of this treatment is a rigid coil in which the wires cannot be disturbed by subsequent insulating and assembling operations.

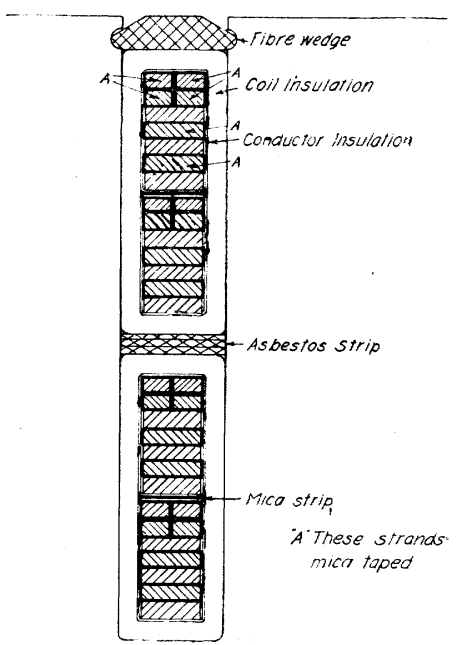

Fig. 4-Section of Armature Slot

The straight coil sides were insulated with a micartafolium wrapper which consists of mica pasted to a very thin paper to give it the necessary mechanical support during the insulation process. The wrapper was first loosely applied to the coil by hand and then ironed into the finished product by electrically heated irons that revolve around the coil softening the bond and exerting a uniform pressure, thus slipping and tightening the wrapper until the insulation takes on the character of a compact wall of mica. The ends of the coil projecting from the core were insulated with mica tape adjacent to the copper and with varnished cloth outside of the mica tape. Varnished cloth tape on the outside of the coil is preferable since it can be sealed to exclude dirt and oil much better than can mica tape. Insulation in the form of narrow tape was used on these parts in order that the ends be flexible.

This insulation was required to meet successfully a dielectric test to ground, and between phases, of thirty thousand volts for one minute. It was also required 
that it safely withstand a maximum total temperature of 150 deg. cent.

(d) The coil ends were bent away from the air gap at an angle of about 45 degrees to provide space below the boreline for the clamping blocks. The coil ends were braced against distortion under short-circuit conditions by clamping them with through bolts between parallel insulating blocks which are bolted to angle-shaped brackets attached to the frame. This construction is shown in the cross-section views of the

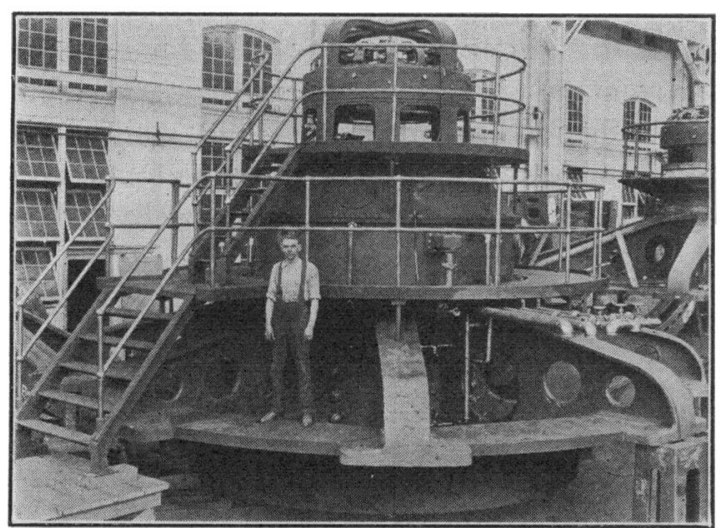

Fig. 5-Upper Bracket with Thrust Bearing, Exciter, Platform and Stairway Assembled

generator, Figs. 1 and 2. It was required that this bracing be capable of supporting the coil ends, with the generator short-circuited at its terminals under full voltage.

\section{DESIGN OF UpPER BEARING BRACKET}

It was required that this member support the combined loads due to the generator rotor, exciter, turbine runner, shaft and unbalanced water thrust amounting to approximately $1,000,000$ pounds. Its design involved the consideration of three principal requirements, namely, (a) the fundamental requirement that it be capable of supporting the load within the safe limits of the material used; (b) that when fully loaded the deflection from the horizontal be less than the clearances between the turbine and generator rotating and stationary parts, and (c) that the character of the material and the design used be such that any vibrations set up by unbalanced conditions in the turbine would not be taken up by the bracket and transmitted to the generator stator.

Obviously these matters are so interwoven that they cannot be considered independently and, therefore, will not be taken up separately.

In designing this supporting member consideration was given to the use of three materials, structural steel, cast steel and cast iron. All factors considered, cast iron seemed the one best suited to the purpose. It was found in considering steel, either structural or cast, that while the requirements of ultimate strength could be readily met, its high degree of flexibility and resilience made it necessary to use sections greatly in excess of the requirement for strength in order to limit the deflection and the possibility of sympathetic vibrations. As the sections required with steel to meet the latter requirements approximated those needed in cast iron for strength, and as cast iron is not as flexible or resilient as steel, the iron was selected.

As the top surface of the upper bracket forms the bottom of the thrust bearing reservoir it is necessary that this casting be impervious to oil leakage. It is very difficult, if not impossible, to obtain steel castings that will entirely meet this requirement whereas there is no difficulty in obtaining cast iron that is perfectly homogeneous and oil tight. As the matter of oil leakage is one of no small importance in the operation of such a unit this was also a deciding factor in determining the selection of the bracket material.

This bracket, Fig. 5, in the finished design used sections approximately 2 inches thick and a maximum height at point of load application of $5 \frac{1}{2}$ feet.

\section{Design of Rotating SPIDER}

Owing to the physical dimensions of the rotating spider the particular problem in the design was to select a construction in which the material throughout would be of uniform quality. On account of the well-

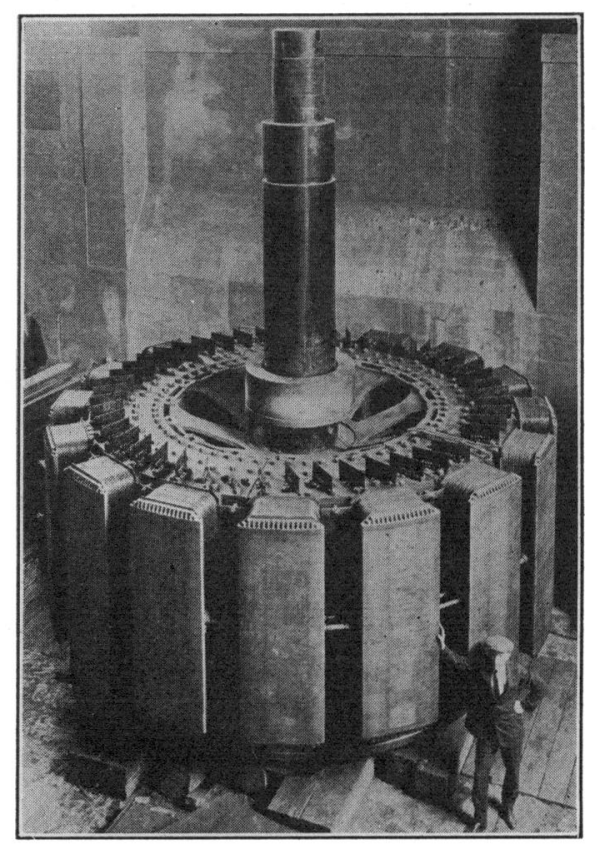

Fig. 6-Rotating Part

known difficulties in making castings of such large sections and of obtaining uniformly homogeneous metal, it was impossible to make the spider of the ordinary "cast wheel" type. The "laminated rim" type of design, Fig. 6, was therefore adopted as the one best suited to meet the requirements.

This design used an inner cast steel spider which consists of a hub and arms but has no rim. The rim 
is built up using over-lapping 1/6-in. rolled steel plates that are dovetailed to the spider arms in a manner similar to that used in attaching the armature punchings to the frame. In addition to being attached to the spider by the dovetails, the rim is clamped between heavy steel end plates by means of through bolts that pass through the entire laminated rim and the end plates. This design results in a rim structure of perfectly uniform material of known quality, to a degree impossible to obtain with castings. In this design the rim was not only self supporting as to radial stresses, entirely neglecting the dovetails, but was also capable of carrying the weight of the poles and field coils when operating at a maximum speed of $347 \mathrm{rev}$. per min.

The two large vent spaces provided in the central part of the spider were to provide additional cooling air inlets for this part of the unit.

\section{Operating Results}

With the generators in regular commercial service and operating under rated load, the maximum temp- erature rise measured by embedded temperature detector is 55 deg. cent.

\section{General Dimensions and Weights}

The principal dimensions and weights of the generators are as follows:

Maximum over-all diameter ...... 25 feet.

Height from floor line to top of frame $13 \mathrm{ft} .8$ inches.

Maximum over-all height from floor

line.

$26 \mathrm{ft} .10$ inches

Diameter of shaft at coupling...... $2 \mathrm{ft} .6$ inches

Total weight of copper......... $50,000 \mathrm{lb}$.

Weight of rotating part........ $615,000 \mathrm{lb}$.

Total weight of generator unit..... 1,400,000 lb.

Load on thrust bearing. . . . . . . 1,000,000 lb.

Flywheel effect of rotor........ 21,500,000 lb-ft. ${ }^{2}$

\section{Discussion}

For discussion on this paper see p. 507. 